\title{
Climate Control Load Reduction Strategies for Electric Drive Vehicles in Warm Weather
}

Matthew A. Jeffers, Larry Chaney, and John P. Rugh

National Renewable Energy Laboratory

CITATION: Jeffers, M., Chaney, L., and Rugh, J., "Climate Control Load Reduction Strategies for Electric Drive Vehicles in Warm Weather," SAE Technical Paper 2015-01-0355, 2015, doi:10.4271/2015-01-0355.

Copyright (C) 2015 SAE International

\begin{abstract}
Passenger compartment climate control is one of the largest auxiliary loads on a vehicle. Like conventional vehicles, electric vehicles $(\mathrm{EVs})$ require climate control to maintain occupant comfort and safety, but cabin heating and air conditioning have a negative impact on driving range for all-electric vehicles. Range reduction caused by climate control and other factors is a barrier to widespread adoption of EVs. Reducing the thermal loads on the climate control system will extend driving range, thereby reducing consumer range anxiety and increasing the market penetration of EVs.
\end{abstract}

Researchers at the National Renewable Energy Laboratory have investigated strategies for vehicle climate control load reduction, with special attention toward EVs. Outdoor vehicle thermal testing was conducted on two 2012 Ford Focus Electric vehicles to evaluate thermal management strategies for warm weather, including solar load reduction and cabin pre-ventilation. An advanced thermal test manikin was used to assess a zonal approach to climate control. In addition, vehicle thermal analysis was used to support testing by exploring thermal load reduction strategies, evaluating occupant thermal comfort, and calculating EV range impacts. Through stationary cooling tests and vehicle simulations, a zonal cooling configuration demonstrated range improvement of $6 \%-15 \%$, depending on the drive cycle. A combined cooling configuration that incorporated thermal load reduction and zonal cooling strategies showed up to $33 \%$ improvement in EV range.

\section{Introduction}

As in conventional vehicles, passenger compartment climate control is required in electric vehicles (EVs) for comfort and safety (e.g., demisting and defrosting). A challenge with EVs is that stored electrical energy consumed for climate control can significantly reduce the vehicle driving range. A Ford Focus Electric vehicle tested at Argonne National Laboratory's Advanced Powertrain Research
Facility showed a reduction in range of $53.7 \%$ due to air conditioning (A/C) and 59.3\% due to heating over the Urban Dynamometer Driving Schedule (UDDS) drive cycle [1] , commonly referred to as the FTP72 or LA4 part of the city cycle. A/C and heating have also been shown to reduce the UDDS driving range of a Nissan Leaf by $18 \%$ and $48 \%$, respectively [2]. Combined with concerns about charging times and locations, range anxiety negatively impacts customer acceptance of EVs and the penetration of these vehicles into the national automotive fleet.

The impact of climate control on range affects traction battery size. Larger batteries are often required to meet range targets that include climate control operation. Depending on the battery location and cooling strategy, the cabin climate control system can also impact battery temperature. Higher lithium-ion battery temperatures can lead to degradation and reduced life of the battery [ $\underline{3}]$. Designing batteries to account for high-temperature degradation also leads to larger and higher-cost batteries, resulting in a cost premium for EVs.

The objective of this research is to increase in-use EV range by minimizing climate control energy requirements. This range improvement is expected to increase customer acceptance of EVs through the reduction of range anxiety. In addition, improving thermal comfort upon entry into a hot-soaked or cold-soaked vehicle may lead to increased motivation for drivers to adopt EVs and may also improve safety through reduced driver distraction due to thermal stress.

\section{Approach}

Experimental and analytical techniques were used in conjunction to investigate thermal load reduction strategies. Outdoor vehicle testing was conducted at the National Renewable Energy Laboratory (NREL) to establish baseline climate control performance for the validation of thermal models and to evaluate vehicle technologies. 
Computer modeling and analysis were used to explore load reduction strategies that are difficult and/or costly to evaluate experimentally and to extrapolate test results to estimate impact on EV range.

\section{Thermal Analysis}

\section{Model Development and Validation}

Thermal analysis tools (including computational fluid dynamics (CFD), heat transfer, and human thermal comfort software) were used to evaluate the effectiveness of potential strategies to reduce the climate control loads. The strategies were considered beneficial if they used less energy while maintaining or improving thermal comfort. Under a cooperative research and development agreement, Ford provided the computer-aided design (CAD) geometry of a Focus Electric. Using this geometry, RadTherm and CFD meshes were developed. These meshes are fundamentally different as CFD uses a volume mesh, and RadTherm uses a surface mesh. Thermal soak and transient cool-down simulations were performed to validate the model to test data. After validation, the model was used to evaluate thermal load reduction strategies through cool-down and human thermal comfort simulations.

\section{RadTherm/Fluent Co-Simulation Methodology}

The thermal analysis simulation methodology is illustrated in Figure 1. The two simulation tools exchange boundary conditions, and thermal comfort is calculated as a post processing step.

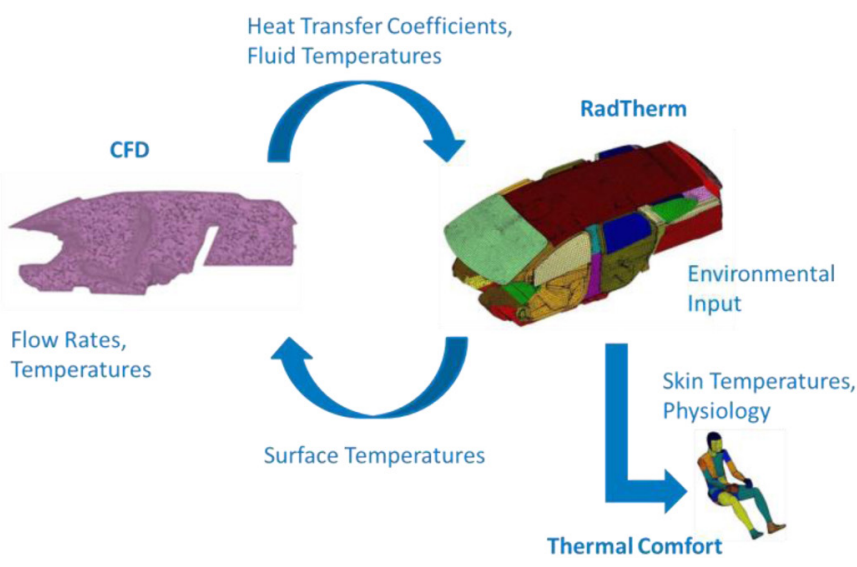

Figure 1. RadTherm/Fluent analysis methodology

The thermal model included a numerical representation of a vehicle passenger compartment. The numerical representation consisted of a surface mesh with 100k shell elements as shown in Figure 1. The thermal modeling tool used for this analysis was RadTherm (version 11), developed by ThermoAnalytics, Inc. (TAI). In the analysis, the heat transfer between the interior and environment was calculated. Inputs to the model included vehicle geometry, material properties, including glass properties, and environmental (weather) data. RadTherm has the capability to apply measured solar and environmental data (from NREL's test site in Golden, Colorado) to the model so that the analysis used the same solar and weather conditions under which the vehicle testing was performed. Heat transfer coefficients on the interior surfaces and interior air temperatures were computed during CFD simulations and then mapped to the RadTherm model.
The CFD tool used for this analysis was Fluent (version 14.5), developed by ANSYS, Inc. A numerical representation of the cabin air volume was also developed using the model provided by Ford. The numerical representation was a volume mesh (up to 10 million cells) of tetrahedral cells, with prism cells in the boundary layer. Figure 1 shows a section cut of this mesh through the driver seat. The flow rate of natural air infiltration through the model was based on measurements performed on the test vehicles and was approximately one-third air volume change per hour. The temperatures of all surfaces in the model were mapped from results of the RadTherm simulation. The results of the Fluent simulation were used to map fluid temperatures and calculated heat transfer coefficients to the RadTherm model.

A virtual manikin based on the geometry of NREL's ADAM thermal manikin was added to both the RadTherm and Fluent models. The virtual manikin is a key element for enabling the human thermal comfort analysis. The virtual manikin seated in the vehicle model is shown in Figure 2.

Thermal comfort analysis was performed with RadTherm and TAI's human thermal comfort plugin. The plugin uses a human physiology model and calculates heat loss or gain to the environment to predict the thermal sensation and thermal comfort of a human. Inputs to the model included a clothing ensemble and metabolic rate. Thermal boundary conditions included the local air velocity and temperatures from around the virtual manikin calculated in Fluent. Several thermal sensation and comfort metrics were output by the thermal comfort analysis, including Berkeley sensation and comfort, predicted mean vote (PMV), predicted percentage dissatisfied (PPD), and dynamic thermal sensation (DTS).

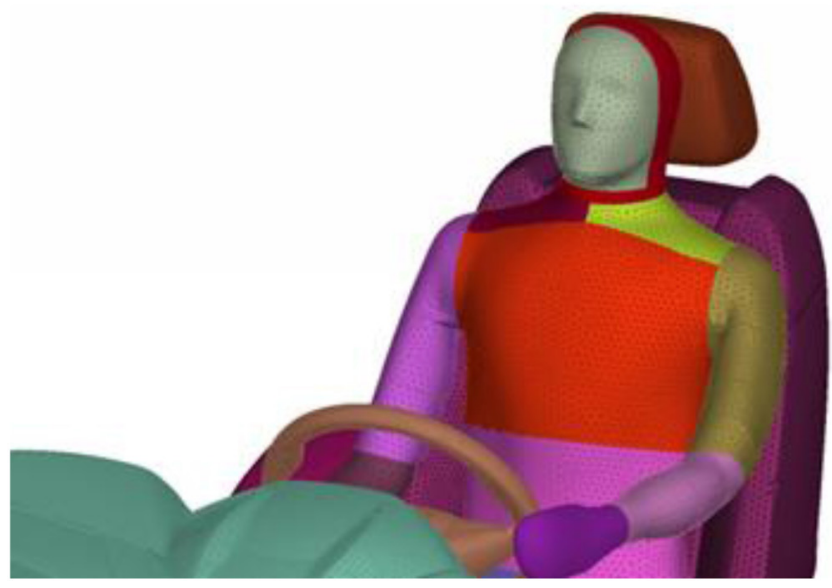

Figure 2. Virtual manikin in driver seat

\section{Baseline Model Validation: Hot Thermal Soak}

A steady-state soak simulation was performed to check the accuracy of the model and to obtain an initial state for the cool-down simulation. The environmental (weather) conditions were obtained from the NREL weather station in Golden, Colorado, for the baseline thermal soak test day of July 3, 2013. The thermal soak test period ended at noon mountain standard time (MST), so the weather data were averaged from 11:40 a.m. to $12 \mathrm{p} . \mathrm{m}$. The average conditions used for the baseline simulation were: ambient temperature of $26.4^{\circ} \mathrm{C}$ $\left(79.5^{\circ} \mathrm{F}\right)$, ambient relative humidity of $28.7 \%$, solar irradiance of $1003.1 \mathrm{~W} / \mathrm{m}^{2}$, and wind speed of $2.4 \mathrm{~m} / \mathrm{s}$. Figure 3 shows the interior 
temperatures predicted by the RadTherm model for the thermal soak simulation. The roof, pillars, and doors are not shown for clarity. Note the shadow cast by the A-pillar on the passenger seat cushion. As expected, the instrument panel has the highest temperatures during thermal soak due to the direct solar radiation exposure.

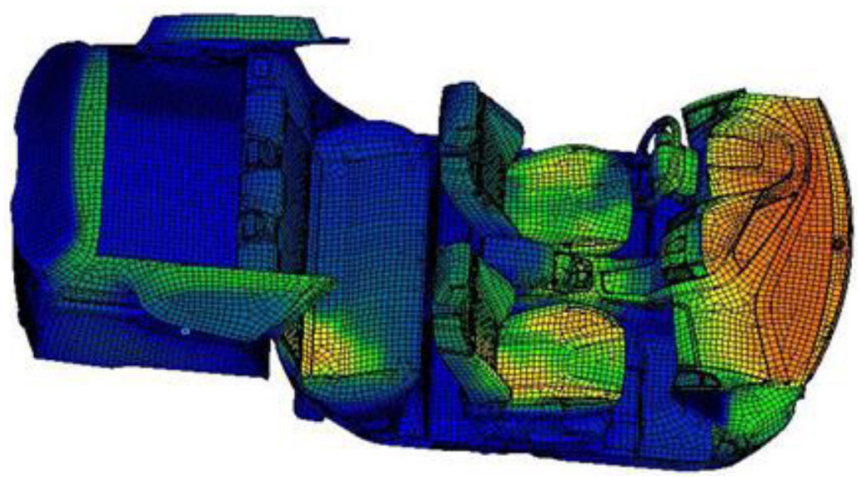

Figure 3. RadTherm predicted surface temperatures

Figure 4 shows the air temperatures predicted by Fluent on a plane passing through the driver seat. The air temperatures show stratification with hotter temperatures near the roof and windshield.

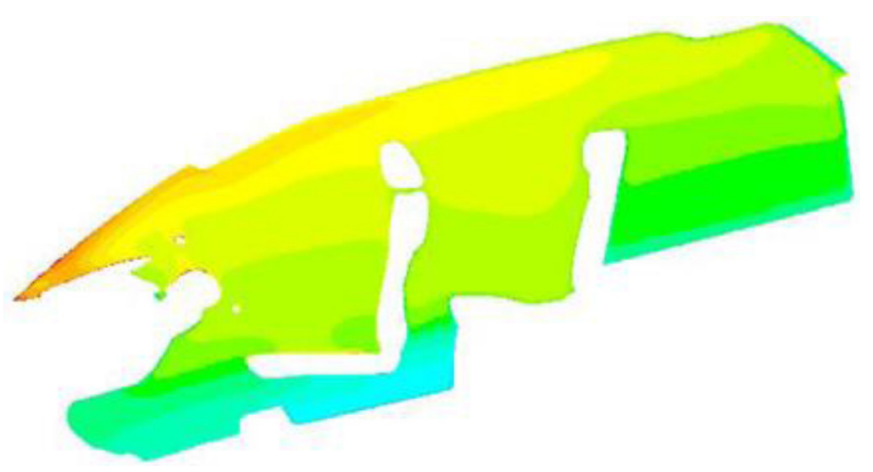

Figure 4. Fluent predicted air temperatures

The steady-state simulation temperatures were compared to thermal soak test data from July 3, 2013, averaged over 20 minutes from 11:40 a.m. to 12 p.m. MST. Minor adjustments were made to model parameters such as material properties or thicknesses to improve correlation of model results to test data.

The baseline soak analysis temperatures in Figure 5 compared favorably to the test data. The most important locations (air, dash, windshield, and driver seat) matched well. The average difference in air temperature for the breath-level locations was $2.64^{\circ} \mathrm{C}$ and the average difference for the foot-level locations was $0.02^{\circ} \mathrm{C}$. Locations that are partially shaded by other vehicle components can be challenging for comparison of the test and analysis data. For example, as the sun moved to the right side of the south-facing car, the passenger seat has a shadow cast on it by the A-pillar. Caution must be used when comparing partially shaded locations.

The close match of the results to thermal soak test data validated the inputs to the steady-state model. These results were used as the initial conditions for the baseline transient cool-down simulation.

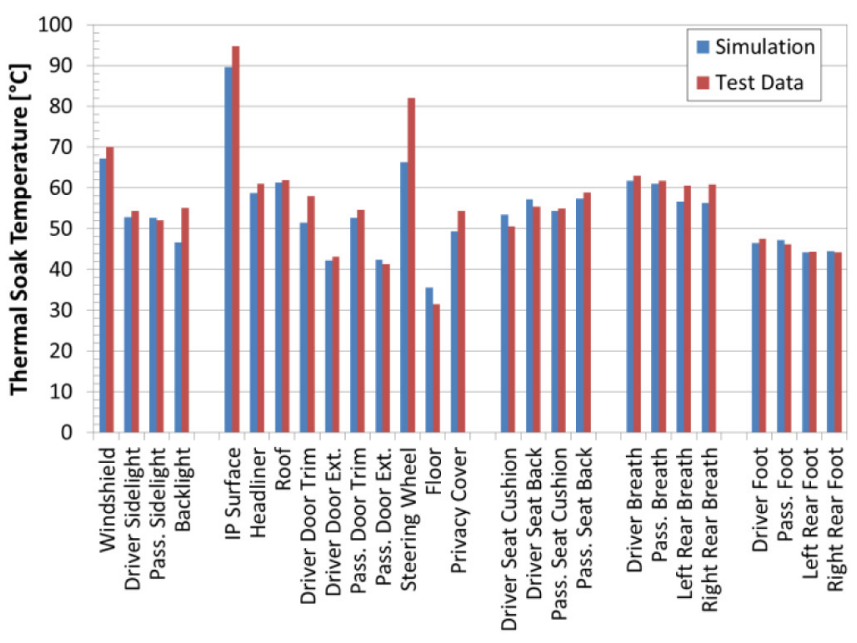

Figure 5. Baseline comparison of simulation temperature results to test data

\section{Baseline Model Validation: Transient Cool-Down}

A transient cool-down simulation was also performed and compared to test data to validate the baseline vehicle model. Experimental data from July 3, 2013, were used, and the simulation was compared to data for the first 20 minutes of the cool-down beginning at $12 \mathrm{p} . \mathrm{m}$. The simulation used the same $\mathrm{A} / \mathrm{C}$ conditions as the cool-down test: maximum $\mathrm{A} / \mathrm{C}$ with the blower on high and $100 \%$ air recirculation. The model used the panel vent inlet velocities obtained from Ford. The transient temperatures at the $\mathrm{A} / \mathrm{C}$ vents were obtained from test data.

Fluent and RadTherm must be run consecutively (not in parallel) and use bidirectional communication. For a steady-state analysis run, this can be done manually, but for a transient analysis run, the process must be automated to maintain time synchronization. A script was developed to execute the Fluent/RadTherm analysis on NREL's Linux supercomputer Peregrine. Using this script, a complete 20-minute transient cool-down analysis can be completed in three days using 128 processors.

Figure 6 and Figure 7 show comparisons of transient temperatures predicted by the simulation to temperature measurements of a cool-down test performed on July 3, 2013.

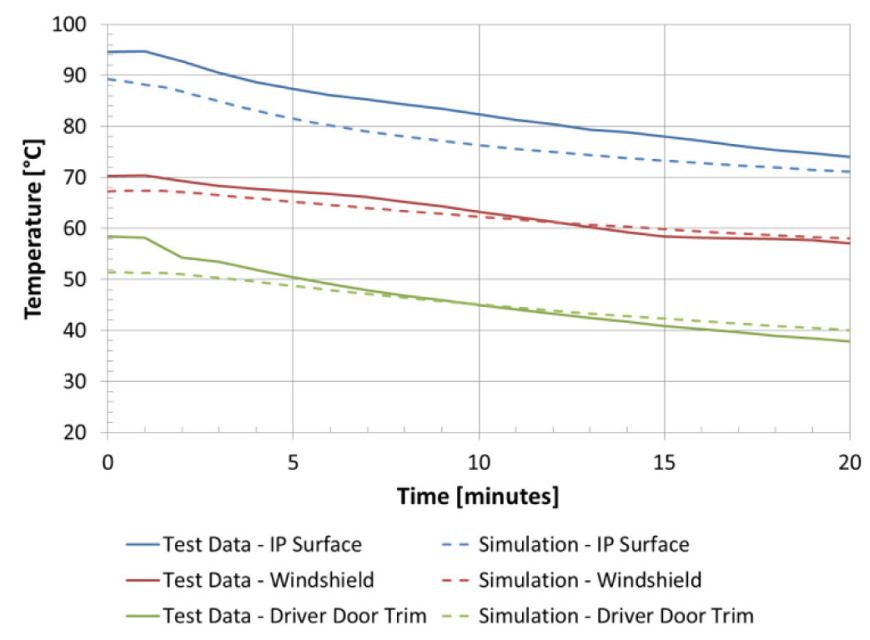

Figure 6. Comparison of cabin surface temperatures from cool-down simulation to measured test data for July 3, 2013 


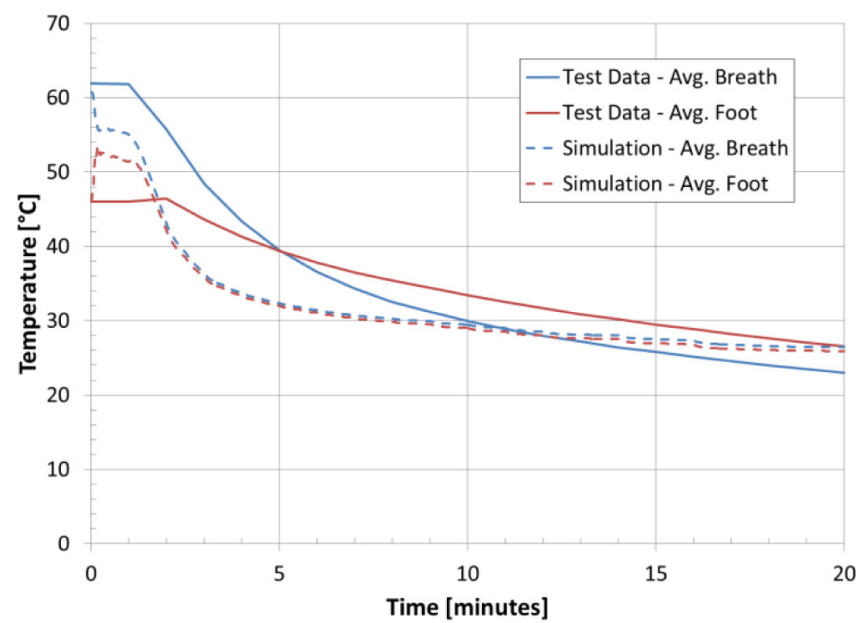

Figure 7. Comparison of cabin air temperatures from cool-down simulation to measured test data for July 3, 2013

The measured and simulated surface temperatures matched well (Figure 6). The simulated air temperatures cooled faster than the test data, resulting in some discrepancy at the start of the cool-down, but the temperatures were within $3^{\circ} \mathrm{C}$ of test data for the second half of the cool-down during the period of interest. The results of the baseline model validation show that the model can predict the thermal conditions of the vehicle after thermal soak and cool-down. The model was used to predict vehicle thermal behavior under conditions that are difficult to test.

\section{Simulated Vehicle Configurations and Results}

\section{Insulated Headliner}

The effect of adding insulation to the headliner was investigated with the validated model. For a sunny environment, adding insulation to the vehicle body may serve to reduce the interior temperature by preventing heat transmission from hot exterior surfaces into the vehicle interior during a hot soak. Conversely, insulation could cause higher soak temperatures by trapping solar energy that is transmitted through the glazing. To evaluate this effect, the headliner insulation was increased by a factor of ten. The remainder of the model and the boundary conditions were the same as those of the baseline case. Figure 8 shows the soak temperatures of the baseline and insulated headliner cases. As expected, for a situation where the baseline roof temperature was hotter than the baseline headliner temperature, the roof temperature increased and the headliner temperature decreased due to the addition of insulation between the two surfaces. The breath-level air temperatures in the case with the insulated headliner were approximately $2^{\circ} \mathrm{C}$ cooler than the baseline case, demonstrating a small, yet positive, impact from insulation for these thermal soak conditions.

Figure 9 shows the temperature difference (baseline minus the insulated case) of several key interior locations during a simulated cool-down. The results show a moderate benefit for the headliner surface temperature but minimal impact to other interior surfaces during a cool-down. There was also a minimal impact to breath-level air temperatures from increasing headliner insulation. This is likely because most of the solar energy still entered the vehicle through the glazing. Therefore, there is little benefit to A/C energy use during cool-down by adding headliner insulation for high solar and moderate ambient temperature conditions, unless the transmitted solar energy is reduced through glazing improvements.

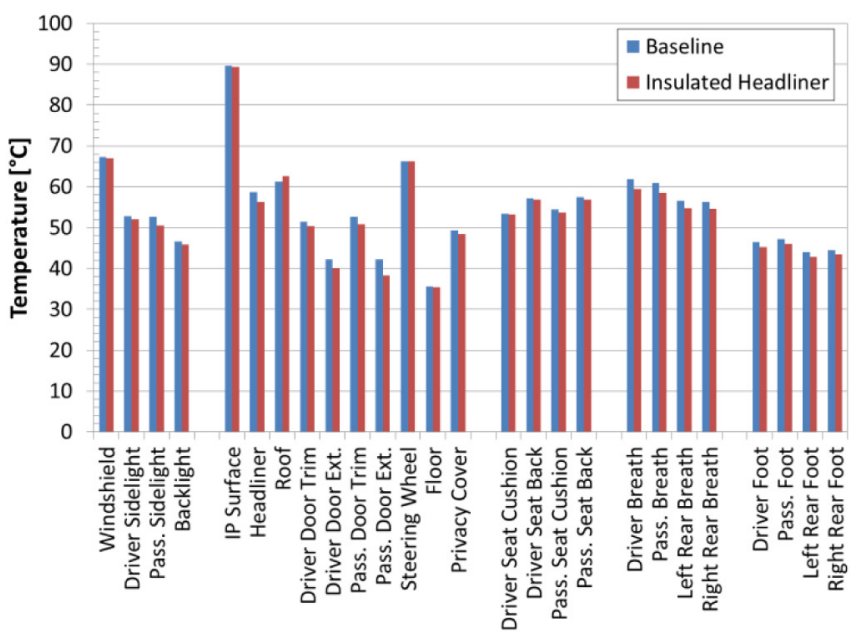

Figure 8. Comparison of soak temperatures for baseline and insulated headliner cases

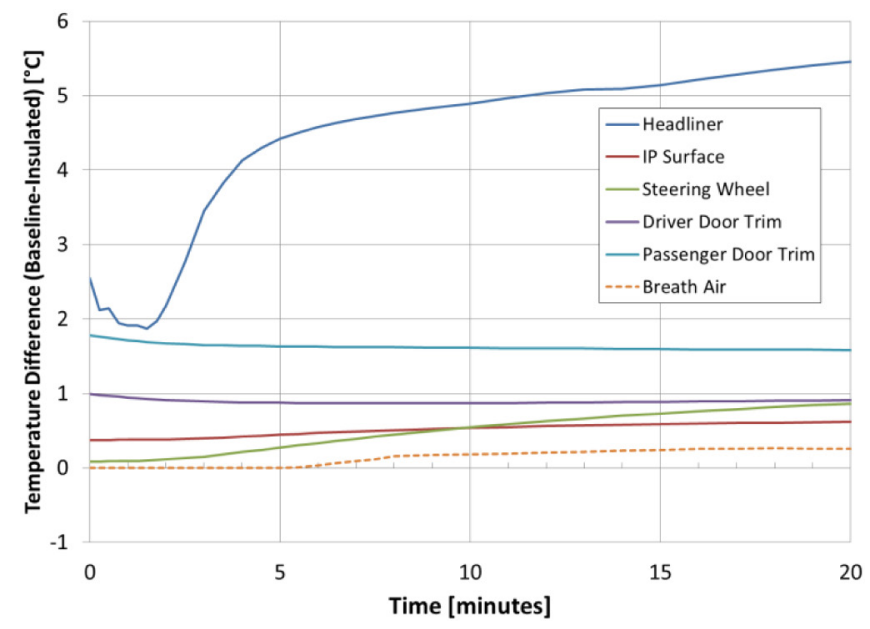

Figure 9. Cabin temperature differences with insulated headliner

Although this analysis showed little benefit from adding insulation during transient cool-down, there may be significant benefit from insulation for transient heating scenarios because the temperature difference between the ambient and cabin set point is greater in a cold environment and there is no thermal penalty from solar gain during a cold thermal soak. The effect of adding body insulation for a cold weather case will be investigated during additional heating mode simulations.

\section{Overhead A/C Vent}

Previous testing and simulation results indicated a potential for an overhead $\mathrm{A} / \mathrm{C}$ vent to enable reduction in $\mathrm{A} / \mathrm{C}$ energy use. An OEM-quality overhead vent was developed during a previous Ford-led thermoelectric heating, ventilating, and air conditioning (HVAC) project [4]. This overhead vent geometry and ducting were incorporated into the Focus Electric model as shown in Figure 10 and Figure 11. The use of this vent geometry enabled a realistic evaluation of this technology. The modified vehicle geometry was remeshed, and both Fluent and RadTherm models were created. 


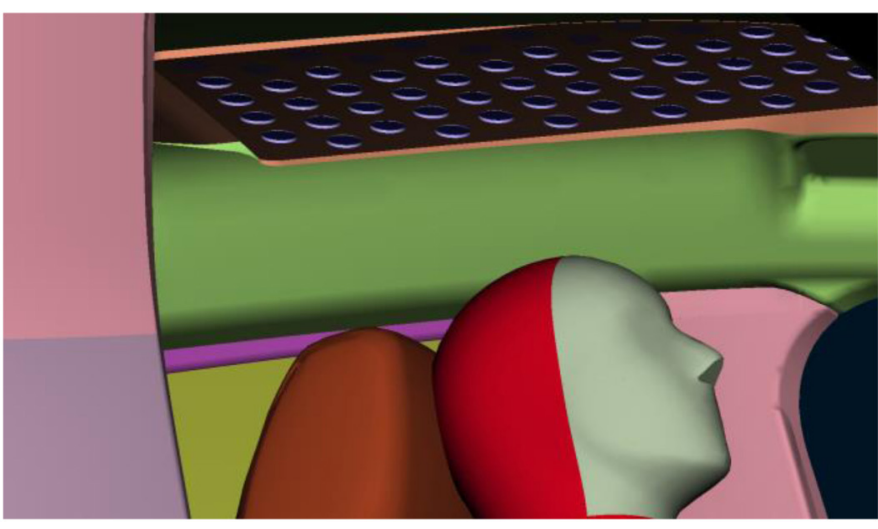

Figure 10. Overhead vent incorporated into the Focus Electric model

In the overhead vent configuration, the air flow to the passenger side panel vents was eliminated, the air flow to the overhead vent was set to 28.3 liters per second ( 60 cubic feet per minute), and the flow to the driver-side panel vents was reduced until thermal comfort matched the baseline case. The resulting air flow rate was $28 \%$ lower than the baseline case. The inlet air temperatures were taken from baseline test data.

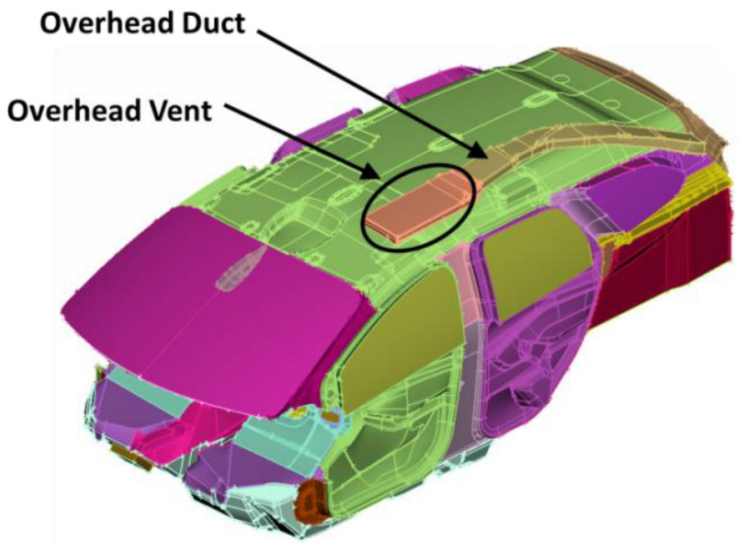

Figure 11. Overhead vent and air duct geometry incorporated into the Focus Electric model

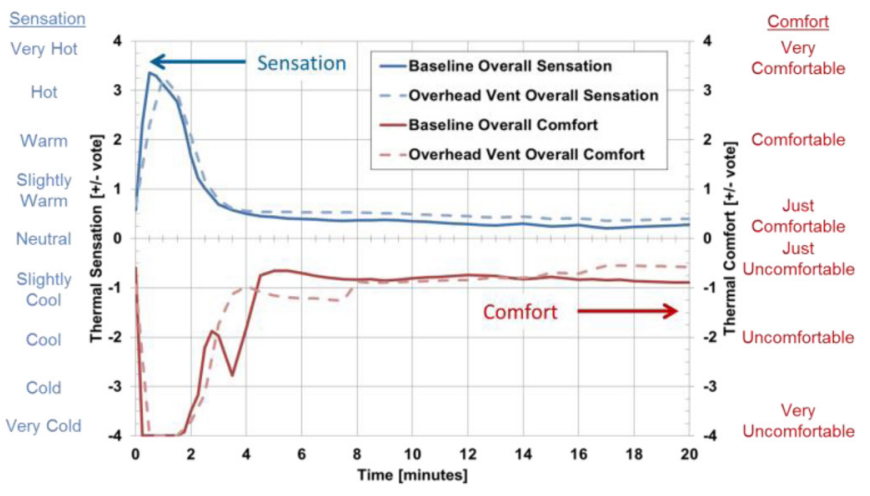

Figure 12. Thermal sensation and comfort results, overhead A/C case compared to baseline

Figure 12 shows the comparison of thermal comfort and sensation for the baseline and overhead vent cases, which match very closely throughout the cool-down. The results show that the $\mathrm{A} / \mathrm{C}$ air flow and thus the $\mathrm{A} / \mathrm{C}$ capacity can be reduced by $28 \%$ while maintaining nearly identical thermal comfort and sensation. Some of the challenges with implementing this type of vent in a production vehicle may include packaging constraints, increased noise concerns, and unwanted heat transfer in the ducts. These results led to the experimental evaluation of this strategy to quantify the impact on $\mathrm{A} / \mathrm{C}$ energy use and EV driving range.

\section{Stationary vs. Moving Vehicle}

For the previous analyses, the thermal model was simulated as a stationary vehicle to match the condition of the vehicle thermal testing conducted at NREL. An additional simulation was performed to assess the impact of a vehicle driving during cool-down compared to a stationary vehicle. The vehicle model was simulated as stationary during thermal soak and moving at a constant 45 -mph velocity during cooldown, with the same ambient conditions as the baseline simulation.

Figure 13 shows a comparison of stationary and moving vehicle glass temperatures, and Figure 14 compares the average breath and foot air temperatures for the two cases. As expected, the glass and air temperatures decrease faster in the moving vehicle due to increased convection on the exterior. The results show that the moving vehicle glass temperatures were significantly lower than for the stationary case, resulting in less heat transferred to the cabin air during cooling.

The average breath air temperature was approximately $5^{\circ} \mathrm{C}$ lower for the moving vehicle after five minutes. Increased exterior convection would lead to a reduced $\mathrm{A} / \mathrm{C}$ load as long as the exterior surface temperatures were higher than the ambient air, which was true for the high solar condition simulated here. For a warm cloudy day, however, increased convection could increase heat transfer from the warm ambient air to the cabin during cooling, causing a higher $\mathrm{A} / \mathrm{C}$ load.

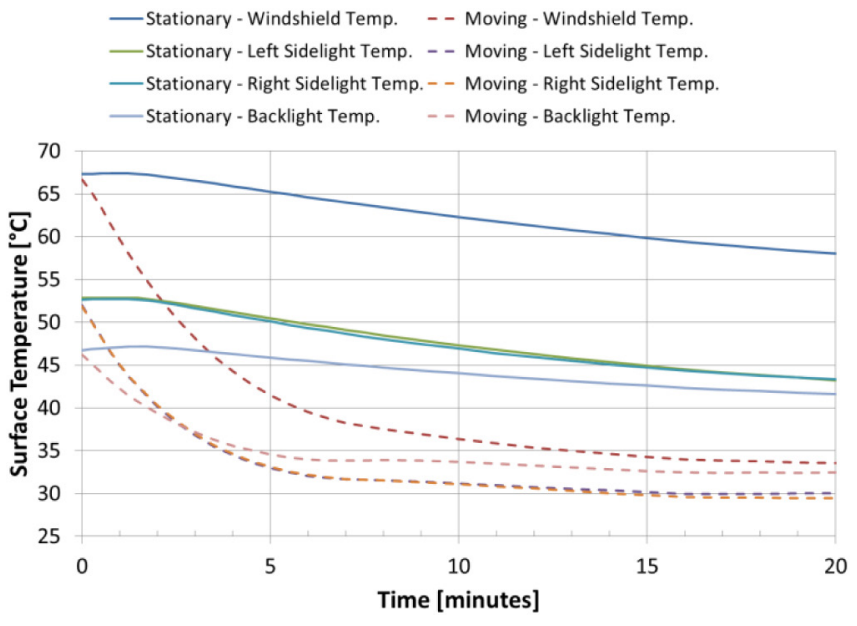

Figure 13. Comparison of glass temperatures during cool-down, stationary vs. moving vehicle

The impact of exterior convection (due to vehicle speed) on $\mathrm{A} / \mathrm{C}$ load during cool-down is dependent on a number of factors, including environmental conditions (solar load, ambient temperature, and wind speed), driving schedule (departure time and drive cycle), HVAC settings, and cool-down time. The complex nature of this issue warrants additional analyses to fully assess the effect of driving a vehicle during cool-down vs. a stationary cool-down for various conditions.

The test results presented in this paper show the thermal behavior of a modified vehicle relative to a control vehicle under the same stationary conditions for all cases. Increased exterior convection would reduce the $\mathrm{A} / \mathrm{C}$ load for both vehicles, but not necessarily by 
the same amount. Different thermal load reduction strategies implemented in the modified vehicle may influence the effect of the convection differently. For example, lowering the cabin temperature during thermal soak reduces the temperature difference between the cabin and ambient air, reducing the amount of convective heat transferred to the ambient during cool-down, compared to the control vehicle. Zonal cooling, on the other hand, may leverage the convective cooling by allowing more stored cabin heat to be transferred to the ambient instead of removed by the $\mathrm{A} / \mathrm{C}$ system.

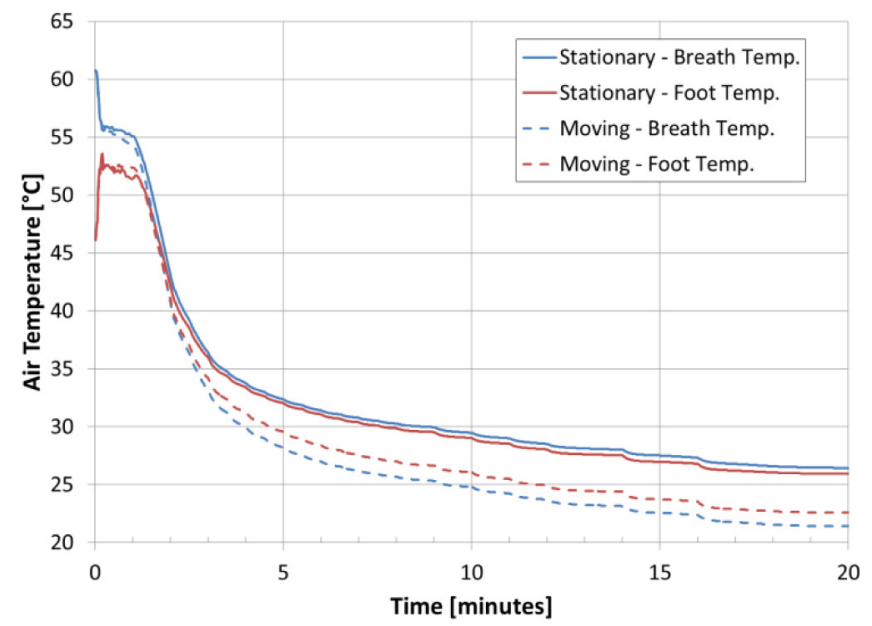

Figure 14. Comparison of cabin air temperatures during cool-down, stationary vs. moving vehicle

Real-world energy savings could be lower than these stationary vehicle test results, but further investigation is needed to quantify the impact of exterior convection on $\mathrm{A} / \mathrm{C}$ load for different test configurations. The impact of vehicle velocity on the $\mathrm{A} / \mathrm{C}$ condenser air flow was not evaluated as part of this investigation.

\section{Vehicle Thermal Testing}

\section{Experimental Test Setup}

Outdoor vehicle testing was conducted at NREL to investigate strategies to reduce electric vehicle climate control loads. Ford provided two 2012 Focus Electric vehicles for this research. The vehicles were parked facing south at NREL's main campus in Golden, Colorado (Figure 15). The vehicles had the same interior and exterior, which produced very similar thermal behavior. One vehicle served as a control vehicle and remained unmodified. The other vehicle was modified to evaluate each climate control load reduction strategy and the results were compared to the control vehicle for each test.

Prior to testing, each vehicle was instrumented with over 40 thermocouples to measure interior and exterior air and surface temperatures. The thermocouples used for measuring cabin air temperatures were fitted with radiation shields. Air temperatures were measured at breath-level height in front of the seat headrest and in the center of the foot well for each of the four primary seats, totaling eight locations in the passenger cabin. The bulk cabin air temperature was the average of these eight temperatures. Power sensors were installed on the high-voltage battery circuit of each vehicle to record HVAC system energy consumption.

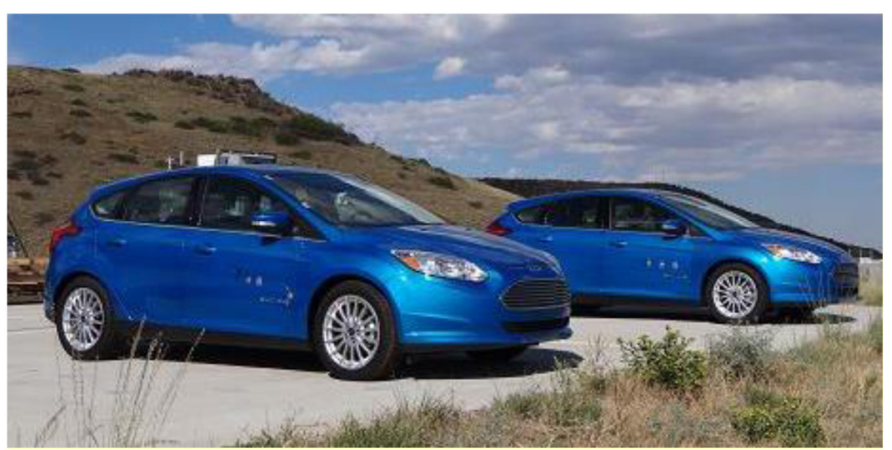

Figure 15. Ford Focus Electric vehicles at NREL's Vehicle Testing and Integration Facility

\section{Test Procedure}

The test procedure developed for warm weather outdoor testing comprised a thermal soak period followed immediately by a transient cool-down. The thermal soak period began before sunrise and lasted until noon MST for each test day. The vehicles remained closed, undisturbed, and exposed to uninterrupted solar loading throughout the thermal soak period. The transient cool-down was initiated at noon in both vehicles simultaneously using the onboard vehicle HVAC systems. The vehicles remained parked during cool-down. The default Max A/C settings for this vehicle were used. These are: maximum blower speed (blower level 7), minimum air temperature set point $\left(\leq 60^{\circ} \mathrm{F}\right)$, maximum air recirculation, and air distribution using the panel vents only.

\section{Baseline Testing}

Twenty-four-hour thermal soak tests were conducted to characterize the baseline performance of the EVs and to identify any inherent differences between them. From 10 a.m. to 4 p.m., the average difference in cabin air temperature between the two EVs was $0.08^{\circ} \mathrm{C}$, and the maximum difference was $0.22^{\circ} \mathrm{C}$. The similar thermal behavior of the EVs verified that the cabin temperatures could be compared directly between the modified and control vehicles with no adjustments necessary.

Baseline transient cool-down tests were also conducted for the EVs prior to beginning technology evaluation. These baseline tests followed the test procedure outlined above, and both vehicles were in the baseline (unmodified) configuration. After 20 minutes of cooling, the average difference in cumulative energy consumption between the EVs was $0.006 \mathrm{kWh}$, with a maximum difference of $0.031 \mathrm{kWh}$, for the two baseline tests. The average difference is less than $1 \%$ of the total cool-down energy use. This close comparison further verified the test methodology of using the control vehicle to quantify performance improvements of the modified vehicle for each test configuration.

\section{Test Configurations and Results}

\section{Thermal Load Reduction}

The thermal load reduction strategies evaluated include technologies to reduce solar loading on the vehicle and strategies to "pre-ventilate" the vehicle cabin. Solar-load reduction technologies decrease the amount of solar energy that is transmitted into the cabin. Preventilation removes stored energy from the cabin prior to $\mathrm{A} / \mathrm{C}$ to reduce the thermal load on the HVAC system. 


\section{Cabin Pre-Ventilation}

Pre-ventilation was achieved using the onboard HVAC blower, existing air ducts, and standard vent configuration with air dampers in maximum outside air mode (minimum cabin air recirculation). The HVAC blower was powered externally and set to the maximum speed (blower level 7). The two pre-ventilation strategies investigated are depicted graphically in Figure 16. For the "just-in-time" (JIT) pre-ventilation strategy, the blower was turned on at a predetermined time prior to the end of the thermal soak period. Pre-ventilation for 15- and 30-minute durations were evaluated.

For the "temperature-controlled" (T-ctrl) ventilation strategy, the blower was activated automatically according to a pair of temperature set points and allowed to operate continuously, cycling on and off throughout the thermal soak period. When the cabin air temperature reached the upper set point, the blower turned on and began removing hot air from the vehicle cabin by displacing it with cooler ambient air. When the lower set point for cabin air temperature was reached, the blower was turned off. This strategy was evaluated using an upper set point of $15^{\circ} \mathrm{C}$ above ambient temperature and a lower set point of $10^{\circ} \mathrm{C}$ above ambient.

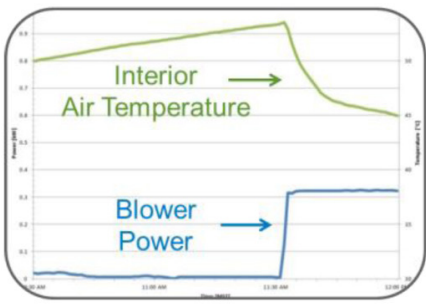

Just-in-Time Ventilation

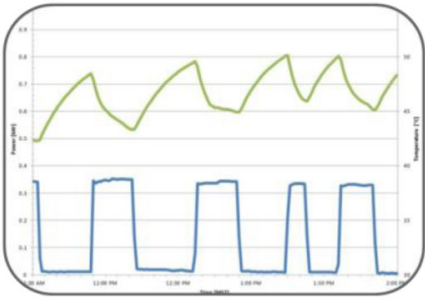

Temperature-controlled Ventilation
Figure 16. Cabin pre-ventilation strategies

The results of the pre-ventilation testing are shown in Figure 17. JIT pre-ventilation for 15- and 30-minute durations achieved cabin air temperature reductions of $7.0^{\circ} \mathrm{C}$ and $8.0^{\circ} \mathrm{C}$, respectively, measured just before the start of cool-down at 12 p.m. Shown for comparison, a continuous ventilation case operating for 3.5 hours using the same blower speed as the JIT strategy resulted in an air temperature reduction of $9.5^{\circ} \mathrm{C}$. This represents the maximum temperature reduction and highlights the diminishing returns of JIT cabin ventilation. Ventilating for 15 minutes achieved a large fraction of the potential air temperature reduction for a small energy input to operate the HVAC blower. The soak temperature reduction for the temperature-controlled ventilation strategy was also measured at 12 p.m., just before cool-down. T-ctrl pre-ventilation reduced the cabin air temperature by $6.7^{\circ} \mathrm{C}$ - nearly as much as 15 minutes of JIT pre-ventilation — but the energy expenditure was significantly higher because the blower operating time was longer. This strategy consumed more energy than JIT ventilation, but had a greater impact on vehicle mass temperatures. Ventilating periodically throughout thermal soak with the T-ctrl strategy reduced the temperature of the instrument panel (IP) cross beam by $6.7^{\circ} \mathrm{C}$. Fifteen minutes of JIT ventilation reduced the cross beam temperature by $3.3^{\circ} \mathrm{C}$. The T-ctrl strategy also has the advantage of operating continuously without the need to monitor or initiate ventilation remotely prior to departure. Thus, the vehicle is ready whenever the driver is.

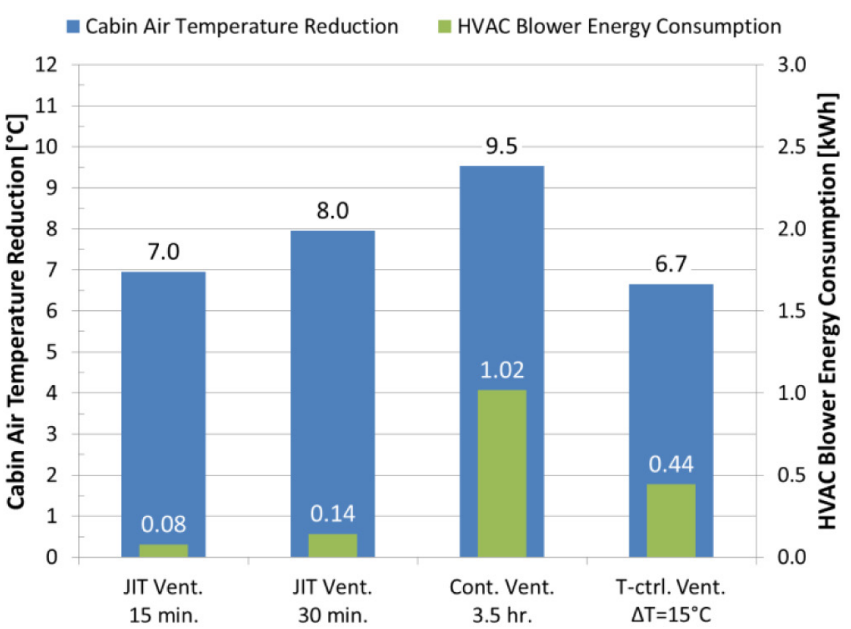

Figure 17. Soak temperature reduction and HVAC blower energy consumption for pre-ventilation test cases

\section{Solar Load Reduction}

The solar load reduction configurations that were evaluated are displayed in Figure 18 and include (clockwise from top left): 1) a shading canopy, 2) white glazing film, 3) solar-reflective glazing film, and 4) an infrared-reflective (IRR) windshield. The shading canopy blocks all direct solar energy from the entire EV (glazing and opaque surfaces) during thermal soak. This was intended to represent the maximum solar load reduction possible by parking under a carport or large tree, for example. The visibly opaque white glazing film was applied to all vehicle glazing and was used to represent the solar load reduction potential of exterior glazing shades that could be used while a vehicle is parked. The solar-reflective glazing film was also applied to all glazing, to approximate the realistic application of advanced solar-reflective glazing technology. This film can meet visible light transmission requirements when laminated in an OEM-installed glazing. Lastly, the IRR windshield is an advanced, production-quality windshield that meets automotive safety standards but transmits less solar energy than standard windshields. The IRR windshield configuration used standard automotive glass for all other glazing locations.

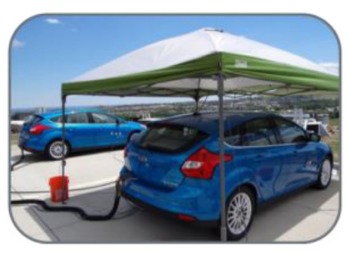

Shading Canopy

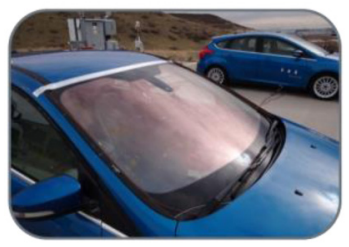

IR-Reflective Windshield

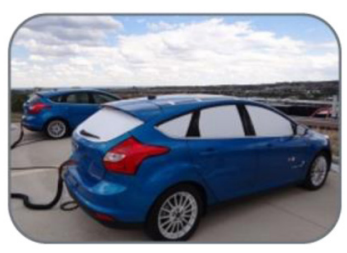

White Glazing Film

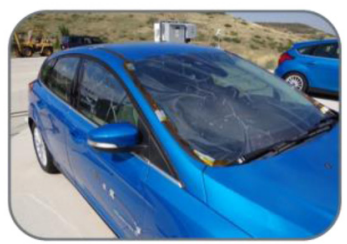

Solar-Reflective Glazing Film
Figure 18. Solar load reduction test configurations

Figure 19 shows the results of the solar load reduction tests in terms of cabin air temperature reduction for the modified EV compared to the control EV at the end of thermal soak. To evaluate the impact of soak temperature reduction on HVAC energy use, a transient 
cool-down was conducted after the thermal soak period for each test configuration. The control EV used the default Max A/C settings as described in the test procedure section above. Because the modified EV started the cool-down with a lower cabin temperature, a reduced blower speed was used during the 20-minute cool-down for each test to decrease the cooling capacity and match the baseline cabin air temperature at the end of the cool-down. This approach lowered energy consumption of the HVAC system while providing equivalent cooling as the control EV. The cool-down energy savings for each test case are also shown in Figure 19. These test results may be higher than for cool-down in a moving vehicle due to the difference in convective heat transfer on the vehicle exterior.

The shading canopy achieved a soak temperature reduction of $18.1^{\circ} \mathrm{C}$, providing a benchmark for the other solar load reduction strategies. This temperature reduction led to $1.20 \mathrm{kWh}$ (nearly $75 \%$ ) less energy consumption for the 20-minute cool-down due to the reduced $\mathrm{A} / \mathrm{C}$ capacity. The white film and solar-reflective film reduced the cabin temperature by $9.2^{\circ} \mathrm{C}$ and $5.3^{\circ} \mathrm{C}$, respectively. These represent passive technologies - window shades and solar-reflective glazing - that require no energy input to reduce the cabin temperature. The IRR windshield achieved a $4.0^{\circ} \mathrm{C}$ temperature reduction and saved $0.21 \mathrm{kWh}$ during cool-down.

The IRR windshield was also evaluated in combination with the 15-minute JIT pre-ventilation strategy discussed previously. This led to a $9.9^{\circ} \mathrm{C}$ reduction in thermal soak cabin temperature and a 0.56 $\mathrm{kWh}(44.2 \%)$ reduction in HVAC energy consumption for a 20-minute cool-down. This strategy combined passive and active solar load reduction technologies that could be widely implemented in vehicles today.

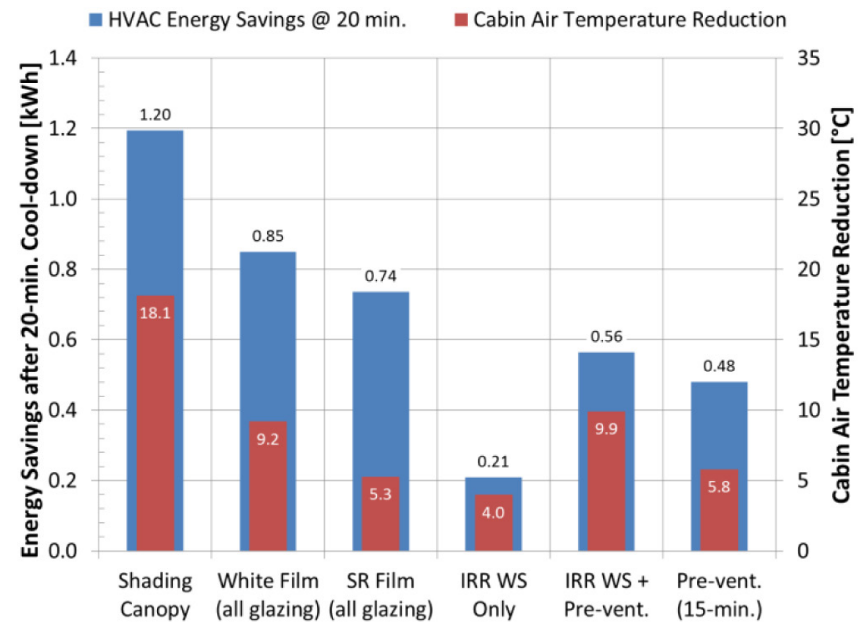

Figure 19. Thermal load reduction test results

The lower thermal soak temperatures of the cabin air and interior surfaces resulting from these thermal load reduction strategies would improve the thermal comfort of an occupant upon entry into a hot-soaked vehicle. The reduced air flow rate used during cool-down for these tests could have a negative impact on occupant thermal comfort, but because the cabin air temperature is lower throughout the cool-down, the overall thermal comfort impact of these strategies is expected to be positive.

The lower soak temperature could lead to a faster cool-down or a reduced cooling rate (lower air flow rate or temperature), depending on the HVAC strategy implemented by the vehicle manufacturer.

\section{Zonal Cooling}

To assess zonal cooling strategies, NREL collaborated with Measurement Technologies Northwest to utilize its Automotive HVAC thermal test manikin. This manikin has a carbon-fiber epoxy shell sized to represent a $50^{\text {th }}$-percentile western male. It has 60 sensors spread around the body form to provide high spatial resolution measurements of the temperature and velocity of air surrounding a vehicle occupant. The manikin was placed in the driver seat of the modified vehicle for all zonal cooling tests. The nearsurface air temperature measurements were averaged to determine the "driver air temperature" for each time step. The driver air temperature was used as a proxy for driver thermal sensation for these tests so zonal cooling could be evaluated for its impact on occupant sensation in addition to HVAC energy use. A baseline cool-down test was conducted with the manikin in the driver seat and the default air vent configuration to establish a baseline driver air temperature after 20 minutes of cooling.

The first zonal cooling configuration utilized the driver vents only. All the passenger air vents were closed, and the default air distribution for Max A/C settings, which uses only the panel vents, was maintained for this configuration. For the second zonal configuration, an overhead $\mathrm{A} / \mathrm{C}$ vent was added near the headliner above the driver seat by extending an air duct from the passenger side panel vent. Cold air from the passenger panel vent was delivered to the head and upper torso area of the driver. The driver panel vents were still active for this case and all other passenger vents remained closed. The third configuration is similar to the second, except the overhead vent was relocated from the headliner to the center console area to deliver cold air to the driver's lap, arms, and lower torso. These three configurations (Figure 20) were tested with the same default Max $\mathrm{A} / \mathrm{C}$ settings (using blower level 7) as the baseline test.

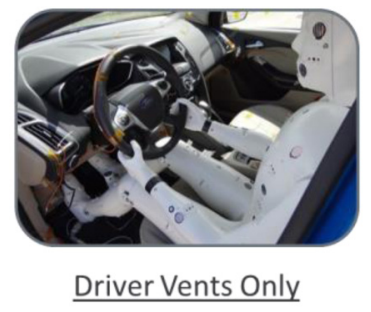

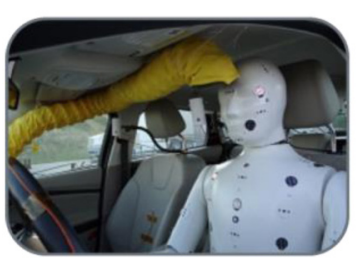

$\underline{\text { Overhead Vent }}$

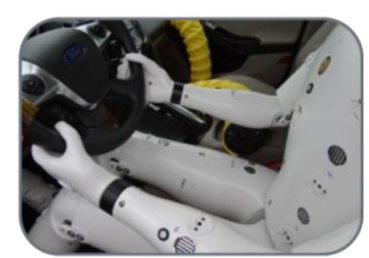

$\underline{\text { Lap Vent }}$
Figure 20. Zonal cooling test configurations

The results are shown in Figure 21 in terms of the driver air temperature (as measured by the HVAC manikin) and the HVAC energy savings of the modified vehicle compared to the baseline vehicle after 20 minutes of cooling with Max A/C settings. The baseline driver air temperature is shown with a dashed line for reference. Using only the driver panel vents for cooling resulted in equivalent driver air temperature, but saved $0.27 \mathrm{kWh}$ of energy due to the reduced $\mathrm{A} / \mathrm{C}$ capacity. The reduced capacity was a result of a lower overall air flow rate, caused by backpressure from the closed 
passenger air vents. Adding an $\mathrm{A} / \mathrm{C}$ vent to the driver's headliner or lap area improved driver cooling by approximately $5^{\circ} \mathrm{C}$ and $4^{\circ} \mathrm{C}$, respectively, and saved $0.12 \mathrm{kWh}$.

Because the first two configurations resulted in a lower driver air temperature than the baseline, these cases were retested with a lower HVAC blower speed (level 5 instead of 7) to provide equivalent driver cooling as the baseline case while achieving greater energy savings.

These tests resulted in significantly higher energy savings. The panel + overhead vent configuration using blower level 5 still achieved better cooling than the baseline. The driver panel vent configuration,

however, did not meet the baseline cooling performance using blower level 5 because the driver air temperature was higher than the baseline after 20 minutes. This configuration was modified by activating the driver foot well vent in addition to the panel vents to increase the zonal cooling effect for the driver. This modified configuration (panel + foot well vent) was tested with blower level 5 and showed a $3{ }^{\circ} \mathrm{C}$ reduction in driver air temperature over the panel vents-only case, approximately matching the baseline case. The reduced $\mathrm{A} / \mathrm{C}$ capacity for this configuration saved $0.58 \mathrm{kWh}$.

Finally, a combined cooling configuration was tested to evaluate the benefit of combining thermal load reduction strategies with zonal cooling. The solar load reduction strategies incorporated into the combined configuration include the advanced IRR windshield in place of the stock windshield and the solar-reflective film applied to the sidelights and backlight. This configuration utilized 15 minutes of JIT cabin pre-ventilation to remove stored energy from the cabin before cool-down. Lastly, a zonal vent configuration that used the overhead vent, the driver panel vents, and the driver foot well vent focused all cold air from the HVAC system onto the driver during the 20-minute cool-down. The blower speed was reduced to level 4 to increase energy savings and avoid overcooling the driver. The result was $0.92 \mathrm{kWh}$ of HVAC energy saved and almost $2^{\circ} \mathrm{C}$ cooler driver air temperature (slight overcooling). These test results represent energy savings for high solar and warm ambient conditions, and the tests focused on transient cooling with maximum A/C settings. Energy savings would be less for more moderate conditions; however, greater energy savings could be realized in more severe hot or humid environments.

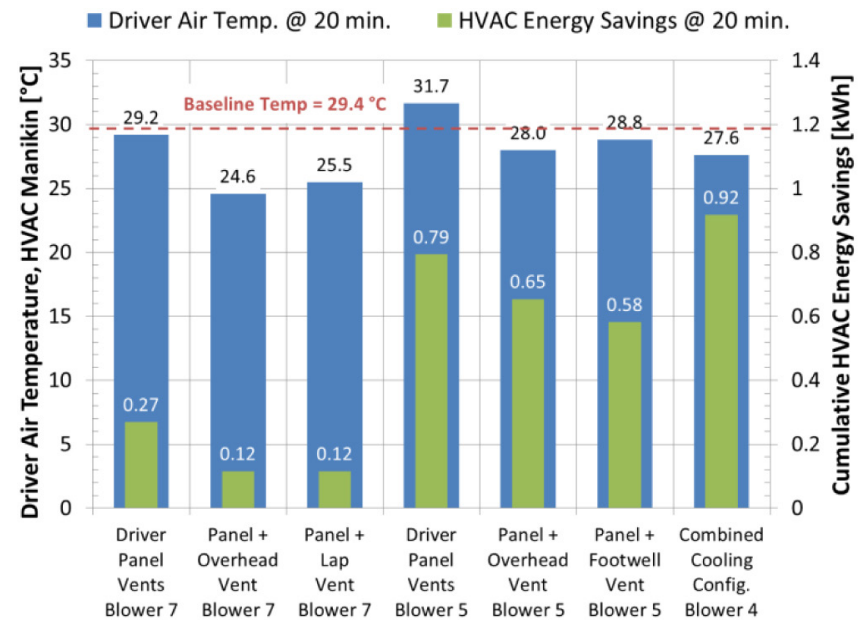

Figure 21. Zonal cooling and combined cooling test results

\section{Vehicle Range Impact Analysis}

\section{Methodology/Approach}

The vehicle simulation tool Autonomie was used to assess the impact of climate control on range. Argonne National Laboratory provided NREL with a model of the Focus Electric. The model was modified to enable input of measured $\mathrm{A} / \mathrm{C}$ compressor power from vehicle tests. Four conditions were compared: no $\mathrm{A} / \mathrm{C}$, baseline $\mathrm{A} / \mathrm{C}$, overhead $\mathrm{A} / \mathrm{C}$, and the combined configuration that included overhead $\mathrm{A} / \mathrm{C}$ and load reduction strategies (glazing and ventilation). The ambient temperature during the outdoor vehicle tests was approximately $27^{\circ} \mathrm{C}\left(80.6^{\circ} \mathrm{F}\right)$ with a solar load of $925 \mathrm{~W} / \mathrm{m}^{2}$. The Focus Electric uses a $23-\mathrm{kWh}$ capacity lithium-ion battery pack. The battery utilization was assumed to be $85 \%$; therefore, $19.55 \mathrm{kWh}$ of usable energy was calculated for the battery pack [1]].

Calculating the vehicle efficiency over a single 10-minute SC03 drive cycle and applying it to calculate the overall range would overestimate the impact of $\mathrm{A} / \mathrm{C}$ because $\mathrm{A} / \mathrm{C}$ loads decrease when the passenger compartment temperatures attain steady state. Because the average vehicle trip duration in the United States is approximately 20 minutes []ㅡ, the average vehicle efficiency was calculated over several drive cycles that lasted approximately 20 minutes. The drive cycles used were: UDDS (22.8 minutes), back-to-back SC03 cycles (19.8 minutes), and back-to-back HWFET cycles (25.5 minutes). The compressor power applied to the model for each case (Figure 22) was a composite profile from test data that included measured compressor power at maximum $\mathrm{A} / \mathrm{C}$ setting for the first 10 minutes (simulating transient cool-down), and measured compressor power for Auto $72^{\circ} \mathrm{F}$ setting for the remainder of the drive cycle (simulating steady-state cooling). This is a more conservative approach than applying the maximum $\mathrm{A} / \mathrm{C}$ compressor profile for the entire 20-minute drive.

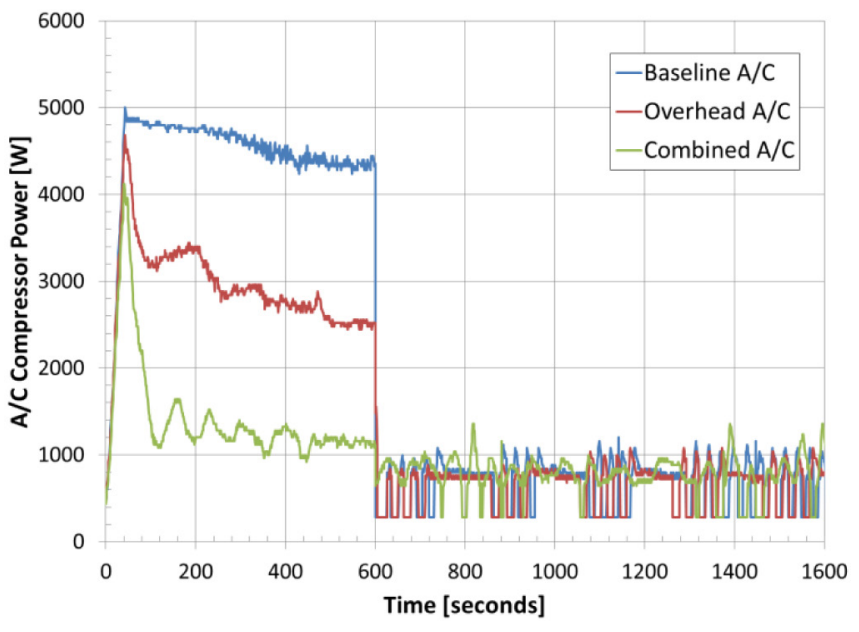

Figure 22. A/C compressor power vs. time for baseline $A / C$, overhead $A / C$ and combined $\mathrm{A} / \mathrm{C}$ test cases

\section{Range Estimation Results}

Table 1 shows the predicted range of the Focus Electric. For the SC03 drive cycle, the baseline $\mathrm{A} / \mathrm{C}$ reduced the range by $37 \%$, from 109.6 to 69.4 miles. The reduction in range using baseline $\mathrm{A} / \mathrm{C}$ varied from $16 \%$ to $37 \%$ for the drive cycles shown. 
Table 1. Predicted Focus Electric driving range (miles)

\begin{tabular}{|l|l|l|l|l|}
\hline Drive Cycle & No A/C & Baseline A/C & Overhead A/C & Combined A/C \\
\hline SC03 & 109.6 & 69.4 & 80.0 & 92.4 \\
\hline UDDS & 111.9 & 70.6 & 81.4 & 93.3 \\
\hline HWFET & 97.6 & 82.2 & 87.1 & 91.3 \\
\hline
\end{tabular}

Table 2 shows the improvement in range over baseline resulting from the overhead vent and the combined configuration. The combined configuration increased the range $11 \%$ to $33 \%$ compared to operation with the baseline A/C system. The percent increase for the HWFET cycle is less than for the other two cycles because the energy needed for propulsion for the high-speed HWFET cycle is much greater than for the low-speed urban cycles, resulting in a smaller percentage of $\mathrm{A} / \mathrm{C}$ energy usage.

Table 2. Predicted driving range improvement over baseline

\begin{tabular}{|l|l|l|l|}
\hline Drive Cycle & $\begin{array}{l}\text { Baseline A/C } \\
(\text { miles })\end{array}$ & $\begin{array}{l}\text { Overhead A/C } \\
(\%)^{\mathrm{a}}\end{array}$ & $\begin{array}{l}\text { Combined A/C } \\
(\%)^{\mathrm{a}}\end{array}$ \\
\hline SC03 & 69.4 & 15.2 & 33.1 \\
\hline UDDS & 70.6 & 15.3 & 32.2 \\
\hline HWFET & 82.2 & 5.9 & 11.2 \\
\hline
\end{tabular}

${ }^{\mathrm{a}} \%$ increase over Baseline $\mathrm{A} / \mathrm{C}$

The range improvement estimates were based on drive cycle simulations using measured weather conditions and A/C power from outdoor vehicle tests. Actual driving range impacts in moderate environmental conditions and for longer or more aggressive drive cycles could be lower.

\section{Summary/Conclusions}

Outdoor vehicle tests, in conjunction with thermal modeling, have been used to assess strategies for reducing vehicle climate control loads. Just-in-time pre-ventilation is an energy-efficient strategy for reducing cabin thermal loads before an anticipated drive. Fifteen minutes of JIT pre-ventilation has been shown to save $0.48 \mathrm{kWh}$ (31.2\%) of A/C energy for a 20-minute cool-down. Implementing this strategy requires a known departure time and the ability to initiate ventilation in advance, either manually from a remote location or automatically according to a programmed schedule. Temperaturecontrolled pre-ventilation is also an effective approach that would be most beneficial for a grid-connected EV to avoid consuming onboard battery power.

Solar load reduction strategies can have a significant impact on $\mathrm{A} / \mathrm{C}$ energy use by reducing vehicle soak temperatures. Shaded parking and opaque window shades lead to the greatest energy savings (over $74 \%$ and $57 \%$, respectively, for a 20 -minute cool-down), but can only be used while a vehicle is parked. Advanced glazing with solarreflective properties must be utilized to reduce transmitted solar energy while a vehicle is in motion. In outdoor vehicle tests, solar-reflective window film used during thermal soak and cool-down resulted in A/C energy savings of approximately $49 \%$. Similarly, an IRR windshield alone produced over $21 \%$ energy savings. Advanced glazing technologies require no actions on the part of the vehicle operator to be effective.

Combining passive strategies (such as solar-reflective glazing) with active strategies (cabin pre-ventilation) to lower vehicle soak temperatures leverages synergistic effects that lead to higher thermal load reduction. A test with an IRR windshield and 15 minutes of JIT pre-ventilation led to $0.56 \mathrm{kWh}(44.2 \%)$ reduction in $\mathrm{A} / \mathrm{C}$ energy.
Zonal cooling has been demonstrated to provide equivalent or better cooling to a driver while enabling the reduction of air conditioning energy consumption for a 20-minute transient cool-down. Test results showed $0.12-0.65 \mathrm{kWh}(7.4 \%-41.3 \%)$ energy savings during cool-down for the same thermal soak conditions. Zonal cooling can be achieved to various degrees by using existing ductwork and adjusting only the air flow distribution, or by incorporating new air ducts and vents into the design to focus cool air near the occupant(s).

The most effective solution for reducing climate control loads in warm weather incorporates thermal load reduction strategies to reduce cabin soak temperatures as well as zonal cooling strategies to efficiently cool the vehicle occupant(s). The combined configuration cooling concept tested at NREL demonstrated the potential for up to $0.92 \mathrm{kWh}(66.5 \%)$ energy savings for a 20-minute cool-down after hot thermal soak. Through vehicle simulations, this was estimated to increase EV driving range by $11 \%-33 \%$. Energy savings from HVAC load reduction solutions translate directly into increased energy for vehicle propulsion, which improves driving range for EVs and can lead to wider EV adoption.

\section{References}

1. Rask, E., "Ford Focus BEV In-depth (Level 2) Testing and Analysis," Presented at Vehicle Systems Analysis Technical Team (VSATT) meeting, Apr. 2014.

2. Slezak, L., "EV Everywhere Grand Challenge: Auxiliary Systems Energy Requirements," Presented at EV Everywhere workshop, Sept. 2012.

3. Electric Vehicle Wiki, "Battery Capacity Loss," http://www. electricvehiclewiki.com/Battery_Capacity_Loss, accessed Jan. 2015.

4. Maranville, C., "Thermoelectric HVAC and Thermal Comfort Enablers for Light-Duty Vehicular Applications," Presented at DOE Vehicle Technologies 2013 Annual Merit Review, May 2013.

5. Santos, A., McGuckin, N., Nakamoto, H.Y., Gray, D., et al., "Summary of Travel Trends: 2009 National Household Travel Survey," Federal Highway Administration, U.S. Department of Transportation, Jun. 2011.

\section{Contact Information}

John P. Rugh

National Renewable Energy Laboratory

15013 Denver West Parkway

Golden, CO 80401

john.rugh@nrel.gov

\section{Acknowledgments}

The authors would like to thank program managers David Anderson and Lee Slezak in the Vehicle Technologies Office, Office of Energy Efficiency and Renewable Energy, U.S. Department of Energy, for sponsoring this research. We would also like to thank the Ford Motor Company for its ongoing support of the project. Lastly, we thank Measurement Technologies Northwest, ThermoAnalytics, Inc., and Argonne National Laboratory for their contributions to this project.

Photo credits: Figure 15, Figure 18, Figure 20 - Matthew Jeffers, NREL 


\section{Definitions/Abbreviations}

HWFET - Highway Fuel Economy Driving Schedule

IP - instrument panel

IRR - infrared-reflective

JIT - just-in-time
OEM - original equipment manufacturer

SC03 - Supplemental Federal Test Procedure (SFTP) drive cycle

T-ctrl - temperature-controlled

TAI - ThermoAnalytics, Inc.

UDDS - Urban Dynamometer Driving Schedule

The Engineering Meetings Board has approved this paper for publication. It has successfully completed SAE's peer review process under the supervision of the session organizer. The process requires a minimum of three (3) reviews by industry experts.

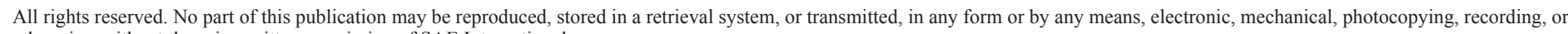
otherwise, without the prior written permission of SAE International.

Positions and opinions advanced in this paper are those of the author(s) and not necessarily those of SAE International. The author is solely responsible for the content of the paper.

ISSN 0148-7191

http://papers.sae.org/2015-01-0355 